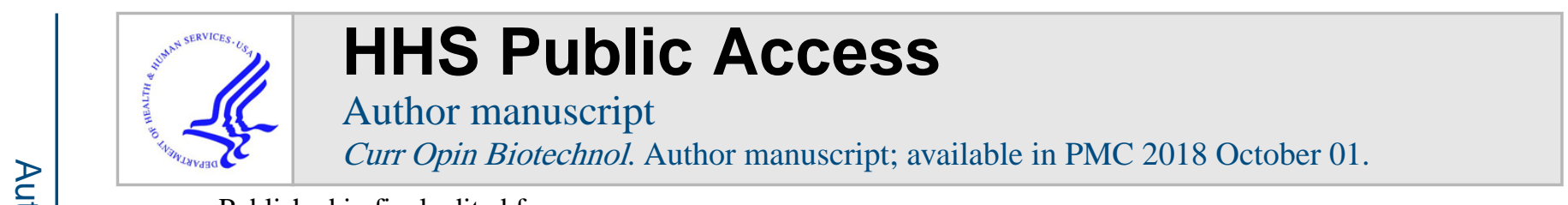

Published in final edited form as:

Curr Opin Biotechnol. 2017 October ; 47: 16-22. doi:10.1016/j.copbio.2017.05.003.

\title{
Biomaterials for Skeletal Muscle Tissue Engineering
}

\author{
Brian J Kwee ${ }^{1,2}$ and David J Mooney ${ }^{1,2}$ \\ ${ }^{1}$ John A. Paulson School of Engineering and Applied Sciences, Harvard University, Cambridge, \\ MA 02138, USA \\ ${ }^{2}$ Wyss Institute for Biologically Inspired engineering, Harvard University, Boston, MA 02115, USA
}

\begin{abstract}
Although skeletal muscle can naturally regenerate in response to minor injuries, more severe damage and myopathies can cause irreversible loss of muscle mass and function. Cell therapies, while promising, have not yet demonstrated consistent benefit, likely due to poor survival of delivered cells. Biomaterials can improve muscle regeneration by presenting chemical and physical cues to muscle cells that mimic the natural cascade of regeneration. This brief review describes strategies for muscle repair utilizing biomaterials that can provide signals to either transplanted or host muscle cells. These strategies range from approaches that utilize biomaterials alone to those that combine biomaterials with exogenous growth factors, ex vivo cultured cells, and extensive culture time.
\end{abstract}

\section{Graphical Abstract}
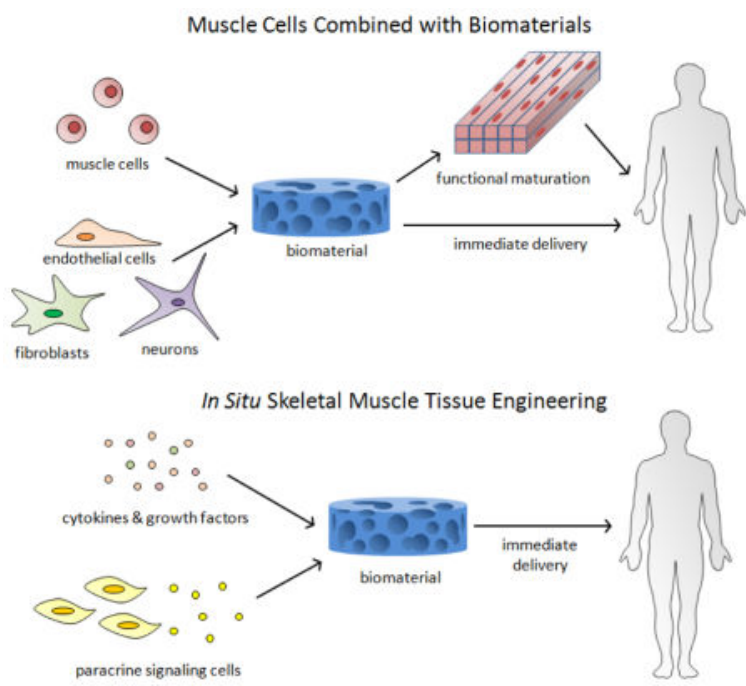

Corresponding Author: Mooney, David J (mooneyd@seas.harvard.edu).

Publisher's Disclaimer: This is a PDF file of an unedited manuscript that has been accepted for publication. As a service to our customers we are providing this early version of the manuscript. The manuscript will undergo copyediting, typesetting, and review of the resulting proof before it is published in its final citable form. Please note that during the production process errors may be discovered which could affect the content, and all legal disclaimers that apply to the journal pertain. 


\section{Introduction}

Skeletal muscle tissue, which comprises about $45 \%$ of total body mass, is necessary for generating forces for movement and locomotion. While skeletal muscle has an inherent ability to regenerate in response to minor injuries, more severe conditions, such as myopathies, substantial traumatic injury, aggressive tumor ablation, and prolonged denervation, result in irreversible loss of muscle mass and function. Deficiencies in regeneration often result in fibrous scar tissue formation and fatty degeneration of muscle.

Current treatments for severe muscle injury and myopathy, including autologous muscle transplantation and injection of ex vivo cultured muscle cells, have shown limited success. Autologous muscle transplants, in the form of free functional muscle transfer, involve removing muscle tissue with intact arties, veins, and nerves at a donor site and surgically connecting at a defect site [1]. This, however, often leads to donor site morbidity and inadequate innervation and perfusion of the transferred muscle. Early clinical trials for duchenne muscular dystrophy, a myopathy that results in progressive muscle wasting, have explored the use of intramuscular injections of cells that could potentially participate in muscle regeneration. However, little benefit was observed, presumably due to the poor survival, migration, and immune rejection of the injected cells [2].

Tissue engineering strategies for skeletal muscle repair that utilize rationally designed biomaterials potentially offer solutions to many of the limitations of current therapies. The biomaterials can provide chemical and physical cues to transplanted or host muscle cells to enhance their survival, promote their functional maturation, protect from the foreign body responses, and recruit host vasculature and nerves into the defect site. This brief review will first provide an overview of the muscle regeneration process and highlight recent findings in this area. It will then review advancements in two general approaches for skeletal muscle tissue engineering. The first, more traditional approach involves combining isolated muscle cells and supporting cells with biomaterials and either directly implanting these cells in vivo at sites of muscle injury or developing the cells into a functional, 3D muscle tissue in vitro prior to implantation (Figure 1A). The second approach, called in situ tissue engineering, involves using biomaterials in combination with cytokines or paracrine signaling cells to drive endogenous regeneration by providing cues to host cells (Figure 1B).

\section{Skeletal Muscle Regeneration}

Following injury, the regeneration of skeletal muscle occurs in different phases that require the action of multiple cell types [3]. During the destruction phase, damaged myofibers and resident inflammatory cells will release soluble factors to further recruit inflammatory cells, such as neutrophils and macrophages, and to activate satellite cells (SC), muscle stem cells found between the basal lamina and sarcolemma of muscle fibers. During the repair phase, activated SCs will divide to either renew the SC niche or differentiate into proliferating myoblasts. In addition, macrophages will clear debris, new capillaries and nerves will invade into the muscle, and fibroblasts will deposit matrix as scar tissue. Finally, during the remodeling phase, proliferating myoblasts will fuse to form new myofibers and scar tissue will be remodeled. Other cell types, such as blood vessel associated mesoangioblasts, 
mesenchymal stem cells, and pericytes, may also contribute to this regeneration process by differentiating into muscle cells [4].

Recent findings on the impact of physical, chemical, and inflammatory cues of the SC niche on muscle regeneration may provide insights for designing new biomaterials for skeletal muscle tissue engineering. The stiffness of the surrounding microenvironment $[5,6]$ and the presence of collagen VI [6] and fibronectin [7] have been shown to regulate the ability of SCs to self-renew. Also, ligands for $\beta 1$-integrin and Notch promote SC quiescence and proliferation [8-10]. Certain inflammatory cytokines also regulate the regeneration process. Eosinophil secreted IL-4 can promote the ability of fibro/adipocyte progenitors to clear muscle debris [11]. Also, T-cell secreted cytokines have been demonstrated to regulate the ability of SCs to contribute to muscle repair in vivo [12,13]. Furthermore, the polarization of macrophages can regulate the fate of muscle precursor cells (MPC), where M1 macrophages have been shown to induce MPC renewal and proliferation, while M2 macrophages promote MPC differentiation [14,15].

\section{Muscle Cells Combined with Biomaterials}

A number of methods for culturing isolated muscle cells on biomaterials in vitro allow one to create functional, self-repairing, engineered skeletal muscle with enhanced vascularization, increased innervation, and morphology similar to native muscle. In one approach, myoblasts seeded into a fibrin gel were cultured under tension between two microposts acting as artificial tendons, resulting in aligned myofibers that generated tetanic forces under stimulation [16]. When seeded with endothelial cells, these 3D constructs also formed aligned vascular networks [17] (Figure 2A). An alternative approach to prevascularize engineered muscle involves seeding endothelial cells, fibroblasts, and myoblasts onto a fibrin-PLG scaffold. Following implantation at a site next to an injury, angiogenesis and anastomosis with the host vasculature were first observed; a subsequent transfer of the scaffold to the neighboring defect site, with the host vasculature still intact, was then demonstrated [18]. 3D, aligned tissue engineered myofibers have also exhibited acetylcholine receptor (AChR) clustering when treated with agrin or laminin [19,20] (Figure $2 \mathrm{~A})$ and this was shown to enhance subsequent innervation and angiogenesis when transplanted in vivo [20]. These engineered myofibers have also been cultured with motor neurons, leading to AChR formation at the interface of the two cell types; these constructs were then able to exhibit contraction when the neurons were activated with glutamic acid [21]. Incorporation of a resident satellite cell niche in muscle constructs has also allowed engineered tissues to exhibit self-repair in vitro [22,23]. Furthermore, 3D muscle tissues have been engineered to more closely mimic native tissue, both in terms of their fiber-like fascicle morphology using sacrificial micro-molding techniques [24,25], as well as their macroscopic scale with 3D-printing technologies [26].

Without extensive in vitro culture, muscle cells are also promising therapies when combined with biomaterial-based growth factor delivery. Macroporous, alginate scaffolds modified with the RGD motif, a peptide that can bind to $\beta 1$-integrin, have been shown to promote the survival and outward migration of primary myoblasts when the scaffolds delivered growth factors for activating the cells [27,28] (Figure 2B). With certain chemical and physical 
modifications, these scaffolds can be made injectable with shape memory properties [29,30], or provide on-demand release of cells and growth factors with externally triggered magnetic fields [31,32]. In vivo, these systems have been shown to enhance the contractile function of severely injured muscle tissue when myoblasts were co-delivered with IGF-1 to promote myogenesis and VEGF to promote angiogenesis $[33,34]$. The importance of concurrently promoting angiogenesis with cell delivery was also shown using delivery of mesoangioblasts expressing placental-derived growth factor (PIGF) inside a PEG-fibrinogen hydrogel; the expression of PIGF led to the formation of new blood vessels and nerves within the newly formed myofibers that were used to replace ablated muscle tissue [35]. In the absence of cues to actively promote angiogenesis, it has been demonstrated that cells delivered progressively in thin fibrin gel layers to a site of volumetric muscle loss allows for host angiogenesis in each new layer, enhancing the survival of the new tissue [36].

\section{In Situ Skeletal Muscle Tissue Engineering}

Biomaterials may also be utilized, with or without controlled growth factor delivery, to drive endogenous skeletal muscle regeneration by activating and/or recruiting host stem cells (Figure 3A). Sustained presentation of VEGF and IGF-1 to ischemic skeletal muscle tissue was shown to enhance myogenesis in injured muscle tissue, while simultaneously promoting tissue survival and function with new capillary and nerve growth [37]. Sustained delivery of VEGF, in particular, has been shown to promote regrowth of damaged axons by upregulating expression of nerve growth factor and glial-derived neurotrophic factor in ischemic tissue [38]. Furthermore, macroporous cryogels with RGD and growth factor incorporation can activate mesenchymal stromal cells to secrete an array of cytokines and growth factors to injured muscle and enhance their contractile function [39]. Controlled delivery of IGF-1 has also been demonstrated to recruit Pax $7+$ muscle cells into a scaffold, resulting in higher muscle formation [40]. Muscle stem cells may also be recruited through the delivery of SDF-1a, which was shown to increase the number of CXCR4+ cells, as well as promote angiogenesis in injured muscle [41]. In a study of volumetric muscle loss (VML), delivery of hepatocyte growth factor enhanced the contractile force of newly formed muscle by increasing the number of differentiated myoblasts and promoting angiogenesis [42].

Scaffolds that allow for cellular remodeling can be used to recruit host cells and regenerate muscle tissue, even in the absence of exogenous growth factors (Figure 3B). Porcine urinary bladder extracellular matrix (ECM) has been used to form new skeletal muscle and treat VML in both rodents and humans; tissue formation was correlated with the recruitment of perivascular stem cells [43]. Fibrin scaffolds with microthread architecture were also shown to treat VML by supporting the ingrowth of nascent myofibers more effectively than nanoporous fibrin gels [42]. Decellularized skeletal muscle matrix injected into ischemic rat hindlimb tissue promoted angiogenesis and increased desmin-positive and MyoD-positive cell infiltration, compared to purified collagen, by enhancing proliferation of skeletal myoblasts [44].

Biomaterial systems can also enhance endogenous muscle regeneration by regulating the type, as well as the amount of inflammation at an injury site (Figure 3C). Decellularized muscle tissue from rabbit was shown to have immunomodulatory effects (e.g., increasing 
M2 macrophage polarization) in a xenograft transplantation model, and to promote antiinflammatory cytokine secretion from T-cells in vitro [45]. An intestinal submucosa ECMderived scaffold promoted M2 macrophage polarization in a VML model, correlating with increased recruitment of perivascular stem cells and cells with neural markers, and enhanced myotube formation [46]. The correlation of M2 macrophage polarization and ECMmediated muscle regeneration was shown to depend on Th2 T-cells, which were required to induce a pro-regenerative response [47,48]. Rationally designed biomaterials for modulating inflammatory responses have also been developed. Material based delivery of FTY720 to traumatic skeletal muscle injury led to recruitment of non-classical monocytes and CD206+ macrophages, which resulted in greater defect closure, more vascularization, improved regeneration of muscle fibers, and decreased fibrotic tissue [49]. Also, materials that provide mechanical compressions of severely injured skeletal muscle were able to reduce fibrosis and inflammation around injured muscle, and increase muscle regeneration and function [50].

\section{Conclusions and Future Directions}

There have been a number of recent advancements in a wide range of biomaterial based strategies for skeletal muscle engineering, ranging from therapies that require a combination of cells, soluble factors, biomaterials, and extensive culture time to therapies that solely rely on a biomaterial. Successful strategies for promoting muscle regeneration will likely need to not only provide cues to promote the proliferation, migration, and maturation of muscle cells, but also regulate angiogenesis, neurogenesis, and inflammatory cues to mimic the natural cascade of muscle regeneration. The necessity of including cells or growth factors into biomaterials will likely depend on the severity and type of injury or myopathy to be treated. The complexity of the approach will ultimately influence the practicality and speed of clinical translation, as will the need for patient specific as versus off-the-shelf therapies.

Moving forward, successful strategies for muscle regeneration may require the combination of different types of material-based strategies, as well as integration of recent fundamental findings in muscle regeneration. For example, the in vivo success of ex vivo cultured engineered tissues will likely require in situ engineering strategies to promote full host and immune integration. Furthermore, combining in situ approaches for recruiting host cells with cell delivery approaches that activate the delivered cells may lead to novel methods of in situ tissue engineering; one potential approach involves developing a material that can recruit satellite cells to a material, activate and induce their proliferation, and then release them into the injured tissue [51,52]. With the growing appreciation of the impact of the immune system on wound healing, vascularization and innervation [53,54], interest in immunomodulatory materials for skeletal muscle engineering is expected to grow. Lastly, material-based strategies may be key to treat age related deficiencies in muscle regeneration, as a growing literature has implicated external cues in these deficiencies. Materials that can regulate tissue mechanics [55], inflammation [56], and integrin engagement [8,57] may enhance the ability of aged satellite cells to contribute to regeneration. 


\section{Acknowledgments}

The authors acknowledge funding from NIHR01 DE013349 to DJM and the NSFGFRP (DGE1144152) to BJK, and thank Herman Vandenburgh for useful discussions.

\section{References and recommended reading}

Papers of particular interest, published within the period of review, have been highlighted as:

- of special interest

•• of outstanding interest

1. Chuang DC-C. Free tissue transfer for the treatment of facial paralysis. Facial Plastic Surgery. 2008; 24:194-203. [PubMed: 18470830]

2. Palmieri B, Tremblay JP, Daniele L. Past, present and future of myoblast transplantation in the treatment of Duchenne muscular dystrophy. Pediatric transplantation. 2010; 14:813-819. [PubMed: 20963914]

3. Järvinen TA, Järvinen TL, Kääriäinen M, Kalimo H, Järvinen M. Muscle injuries biology and treatment. The American journal of sports medicine. 2005; 33:745-764. [PubMed: 15851777]

4. Fishman JM, Tyraskis A, Maghsoudlou P, Urbani L, Totonelli G, Birchall MA, De Coppi P. Skeletal muscle tissue engineering: which cell to use? Tissue Engineering Part B: Reviews. 2013; 19:503515. [PubMed: 23679017]

5. Gilbert PM, Havenstrite KL, Magnusson KE, Sacco A, Leonardi NA, Kraft P, Nguyen NK, Thrun S, Lutolf MP, Blau HM. Substrate elasticity regulates skeletal muscle stem cell self-renewal in culture. Science. 2010; 329:1078-1081. [PubMed: 20647425]

6. Urciuolo A, Quarta M, Morbidoni V, Gattazzo F, Molon S, Grumati P, Montemurro F, Tedesco FS, Blaauw B, Cossu G. Collagen VI regulates satellite cell self-renewal and muscle regeneration. Nature communications. 2013:4.

7. Bentzinger CF, Wang YX, von Maltzahn J, Soleimani VD, Yin H, Rudnicki MA. Fibronectin regulates Wnt7a signaling and satellite cell expansion. Cell stem cell. 2013; 12:75-87. [PubMed: 23290138]

8. Rozo M, Li L, Fan C-M. Targeting [beta]1-integrin signaling enhances regeneration in aged and dystrophic muscle in mice. Nat Med. 2016; 22:889-896. [PubMed: 27376575]

9. Conboy IM, Conboy MJ, Smythe GM, Rando TA. Notch-mediated restoration of regenerative potential to aged muscle. Science. 2003; 302:1575-1577. [PubMed: 14645852]

10. Lin S, Shen H, Jin B, Gu Y, Chen Z, Cao C, Hu C, Keller C, Pear WS, Wu L. Brief report: Blockade of Notch signaling in muscle stem cells causes muscular dystrophic phenotype and impaired muscle regeneration. Stem Cells. 2013; 31:823-828. [PubMed: 23307608]

11. Heredia JE, Mukundan L, Chen FM, Mueller AA, Deo RC, Locksley RM, Rando TA, Chawla A. Type 2 innate signals stimulate fibro/adipogenic progenitors to facilitate muscle regeneration. Cell. 2013; 153:376-388. [PubMed: 23582327]

12. Burzyn D, Kuswanto W, Kolodin D, Shadrach JL, Cerletti M, Jang Y, Sefik E, Tan TG, Wagers AJ, Benoist C. A special population of regulatory T cells potentiates muscle repair. Cell. 2013; 155:1282-1295. [PubMed: 24315098]

13•. Fu X, Xiao J, Wei Y, Li S, Liu Y, Yin J, Sun K, Sun H, Wang H, Zhang Z. Combination of inflammation-related cytokines promotes long-term muscle stem cell expansion. Cell research. 2015; 25:655-673. Demonstrated that application of defined cocktail of T-cell secreted cytokines to mouse muscle precursor cells allows for their long-term expansion and maintains their ability to engraft and contribute to regeneration in vivo. [PubMed: 25976405]

14. Mounier R, Théret M, Arnold L, Cuvellier S, Bultot L, Göransson O, Sanz N, Ferry A, Sakamoto $\mathrm{K}$, Foretz M. AMPKa 1 regulates macrophage skewing at the time of resolution of inflammation during skeletal muscle regeneration. Cell metabolism. 2013; 18:251-264. [PubMed: 23931756]

15. Saclier M, Yacoub-Youssef H, Mackey AL, Arnold L, Ardjoune H, Magnan M, Sailhan F, Chelly J, Pavlath GK, Mounier R. Differentially activated macrophages orchestrate myogenic precursor cell 
fate during human skeletal muscle regeneration. Stem cells. 2013; 31:384-396. [PubMed: 23169615]

16. Vandenburgh H, Shansky J, Benesch-Lee F, Barbata V, Reid J, Thorrez L, Valentini R, Crawford G. Drug-screening platform based on the contractility of tissue-engineered muscle. Muscle \& nerve. 2008; 37:438-447. [PubMed: 18236465]

17. Gholobova D, Decroix L, Van Muylder V, Desender L, Gerard M, Carpentier G, Vandenburgh H, Thorrez L. Endothelial network formation within human tissue-engineered skeletal muscle. Tissue Engineering Part A. 2015; 21:2548-2558. [PubMed: 26177063]

18. Shandalov Y, Egozi D, Koffler J, Dado-Rosenfeld D, Ben-Shimol D, Freiman A, Shor E, Kabala A, Levenberg S. An engineered muscle flap for reconstruction of large soft tissue defects. Proceedings of the National Academy of Sciences. 2014; 111:6010-6015.

19. Wang L, Shansky J, Vandenburgh H. Induced formation and maturation of acetylcholine receptor clusters in a defined 3D bio-artificial muscle. Molecular neurobiology. 2013; 48:397-403. [PubMed: 23371342]

20. Ko IK, Lee B-K, Lee SJ, Andersson K-E, Atala A, Yoo JJ. The effect of in vitro formation of acetylcholine receptor (AChR) clusters in engineered muscle fibers on subsequent innervation of constructs in vivo. Biomaterials. 2013; 34:3246-3255. [PubMed: 23391495]

21. Morimoto Y, Kato-Negishi M, Onoe H, Takeuchi S. Three-dimensional neuron-muscle constructs with neuromuscular junctions. Biomaterials. 2013; 34:9413-9419. [PubMed: 24041425]

22. Juhas M, Engelmayr GC, Fontanella AN, Palmer GM, Bursac N. Biomimetic engineered muscle with capacity for vascular integration and functional maturation in vivo. Proceedings of the National Academy of Sciences. 2014; 111:5508-5513.

23. Madden L, Juhas M, Kraus WE, Truskey GA, Bursac N. Bioengineered human myobundles mimic clinical responses of skeletal muscle to drugs. Elife. 2015; 4:e04885. [PubMed: 25575180]

24. Neal D, Sakar MS, Bashir R, Chan V, Asada HH. Mechanical characterization and shape optimization of fascicle-like 3D skeletal muscle tissues contracted with electrical and optical stimuli. Tissue Engineering Part A. 2015; 21:1848-1858. [PubMed: 25714129]

25. Neal D, Sakar MS, Ong L-LS, Asada HH. Formation of elongated fascicle-inspired 3D tissues consisting of high-density, aligned cells using sacrificial outer molding. Lab on a Chip. 2014; 14:1907-1916. [PubMed: 24744046]

26. Kang H-W, Lee SJ, Ko IK, Kengla C, Yoo JJ, Atala A. A 3D bioprinting system to produce humanscale tissue constructs with structural integrity. Nat Biotech. 2016; 34:312-319.

27. Hill E, Boontheekul T, Mooney DJ. Designing scaffolds to enhance transplanted myoblast survival and migration. Tissue engineering. 2006; 12:1295-1304. [PubMed: 16771642]

28. Hill E, Boontheekul T, Mooney DJ. Regulating activation of transplanted cells controls tissue regeneration. Proceedings of the National Academy of Sciences of the United States of America. 2006; 103:2494-2499. [PubMed: 16477029]

29. Bencherif SA, Sands RW, Bhatta D, Arany P, Verbeke CS, Edwards DA, Mooney DJ. Injectable preformed scaffolds with shape-memory properties. Proceedings of the National Academy of Sciences. 2012; 109:19590-19595.

30. Wang L, Shansky J, Borselli C, Mooney D, Vandenburgh H. Design and fabrication of a biodegradable, covalently crosslinked shape-memory alginate scaffold for cell and growth factor delivery. Tissue Engineering Part A. 2012; 18:2000-2007. [PubMed: 22646518]

31. Zhao X, Kim J, Cezar CA, Huebsch N, Lee K, Bouhadir K, Mooney DJ. Active scaffolds for ondemand drug and cell delivery. Proceedings of the National Academy of Sciences. 2011; 108:6772 .

32. Cezar CA, Kennedy SM, Mehta M, Weaver JC, Gu L, Vandenburgh H, Mooney DJ. Biphasic ferrogels for triggered drug and cell delivery. Advanced healthcare materials. 2014; 3:1869-1876. [PubMed: 24862232]

33. Wang L, Cao L, Shansky J, Wang Z, Mooney D, Vandenburgh H. Minimally invasive approach to the repair of injured skeletal muscle with a shape-memory scaffold. Molecular Therapy. 2014; 22:1441-1449. [PubMed: 24769909] 
34. Borselli C, Cezar CA, Shvartsman D, Vandenburgh HH, Mooney DJ. The role of multifunctional delivery scaffold in the ability of cultured myoblasts to promote muscle regeneration. Biomaterials. 2011; 32:8905-8914. [PubMed: 21911253]

35•. Fuoco C, Rizzi R, Biondo A, Longa E, Mascaro A, Shapira-Schweitzer K, Kossovar O, Benedetti $\mathrm{S}$, Salvatori ML, Santoleri S. In vivo generation of a mature and functional artificial skeletal muscle. EMBO molecular medicine. 2015:e201404062. Incorporated mesoangioblasts expressing placental-derived growth factor into a PEG-fibrinogen hydrogel for the treatment of ablated muscle. Newly formed myofibers were histologically similar to native muscle.

36. Kim JH, Ko IK, Atala A, Yoo JJ. Progressive Muscle Cell Delivery as a Solution for Volumetric Muscle Defect Repair. Scientific Reports. 2016; 6:38754. [PubMed: 27924941]

37. Borselli C, Storrie H, Benesch-Lee F, Shvartsman D, Cezar C, Lichtman JW, Vandenburgh HH, Mooney DJ. Functional muscle regeneration with combined delivery of angiogenesis and myogenesis factors. Proceedings of the National Academy of Sciences. 2010; 107:3287-3292.

38. Shvartsman D, Storrie-White H, Lee K, Kearney C, Brudno Y, Ho N, Cezar C, McCann C, Anderson E, Koullias J. Sustained delivery of VEGF maintains innervation and promotes reperfusion in ischemic skeletal muscles via NGF/GDNF signaling. Molecular Therapy. 2014; 22:1243-1253. [PubMed: 24769910]

39•. Pumberger M, Qazi TH, Ehrentraut MC, Textor M, Kueper J, Stoltenburg-Didinger G, Winkler T, von Roth P, Reinke S, Borselli C. Synthetic niche to modulate regenerative potential of MSCs and enhance skeletal muscle regeneration. Biomaterials. 2016; 99:95-108. Used a macroporous alginate scaffold to provide chemical cues to mesenchymal stromal cells, in order to enhance their paracrine signaling ability to injured muscle. [PubMed: 27235995]

40. Ju YM, Atala A, Yoo JJ, Lee SJ. In situ regeneration of skeletal muscle tissue through host cell recruitment. Acta biomaterialia. 2014; 10:4332-4339. [PubMed: 24954910]

41. Rybalko VY, Pham CB, Hsieh P-L, Hammers DW, Merscham-Banda M, Suggs LJ, Farrar RP. Controlled delivery of SDF-1a and IGF-1: CXCR4+ cell recruitment and functional skeletal muscle recovery. Biomaterials Science. 2015; 3:1475-1486. [PubMed: 26247892]

42. Grasman JM, Do DM, Page RL, Pins GD. Rapid release of growth factors regenerates force output in volumetric muscle loss injuries. Biomaterials. 2015; 72:49-60. [PubMed: 26344363]

43. Sicari BM, Rubin JP, Dearth CL, Wolf MT, Ambrosio F, Boninger M, Turner NJ, Weber DJ, Simpson TW, Wyse A, et al. An Acellular Biologic Scaffold Promotes Skeletal Muscle Formation in Mice and Humans with Volumetric Muscle Loss. Science Translational Medicine. 2014; 6:234ra258-234ra258. Demonstrated the clinical potential of using acellular ECM scaffolds to recruit perivascular stem cells and induce functional recovery in human patients with VML.

44. DeQuach JA, Lin JE, Cam C, Hu D, Salvatore MA, Sheikh F, Christman KL. Injectable skeletal muscle matrix hydrogel promotes neovascularization and muscle cell infiltration in a hindlimb ischemia model. European cells \& materials. 2012; 23:400-412. [PubMed: 22665162]

45. Fishman JM, Lowdell MW, Urbani L, Ansari T, Burns AJ, Turmaine M, North J, Sibbons P, Seifalian AM, Wood KJ. Immunomodulatory effect of a decellularized skeletal muscle scaffold in a discordant xenotransplantation model. Proceedings of the National Academy of Sciences. 2013; 110:14360-14365.

46. Dziki JL, Sicari BM, Wolf MT, Cramer MC, Badylak SF. Immunomodulation and Mobilization of Progenitor Cells by Extracellular Matrix Bioscaffolds for Volumetric Muscle Loss Treatment. Tissue Engineering Part A. 2016; 22:1129-1139. [PubMed: 27562630]

47••. Sadtler K, Estrellas K, Allen BW, Wolf MT, Fan H, Tam AJ, Patel CH, Luber BS, Wang H, Wagner KR. Developing a pro-regenerative biomaterial scaffold microenvironment requires $\mathrm{T}$ helper 2 cells. Science. 2016; 352:366-370. Demonstrated that ECM scaffolds that provide a microenvironment conducive for promoting muscle regeneration require the presense of $\mathrm{Th} 2$ helper T-cells to promote M2 macrophage polarizaton and tissue repair. [PubMed: 27081073]

48. Sadtler K, Allen BW, Estrellas K, Housseau F, Pardoll DM, Elisseeff JH. The Scaffold Immune Microenvironment: Biomaterial-Mediated Immune Polarization in Traumatic and Nontraumatic Applications. Tissue Engineering Part A. 2016

49. San Emeterio CL, Olingy CE, Chu Y, Botchwey EA. Selective recruitment of non-classical monocytes promotes skeletal muscle repair. Biomaterials. 2016 
50••. Cezar CA, Roche ET, Vandenburgh HH, Duda GN, Walsh CJ, Mooney DJ. Biologic-free mechanically induced muscle regeneration. Proc Natl Acad Sci U S A. 2016; 113:1534-1539. Utilized mechanical stimulation of injured muscle, in the absence of biological factors, to reduce fibrosis and inflammation, as well as promote functional muscle regeneration. [PubMed: 26811474]

51. Huebsch N, Mooney DJ. Inspiration and application in the evolution of biomaterials. Nature. 2009; 462:426-432. [PubMed: 19940912]

52. Mooney DJ, Vandenburgh H. Cell delivery mechanisms for tissue repair. Cell stem cell. 2008; 2:205-213. [PubMed: 18371446]

53. Cattin A-L, Burden JJ, Van Emmenis L, Mackenzie FE, Hoving JJ, Calavia NG, Guo Y, McLaughlin M, Rosenberg LH, Quereda V. Macrophage-induced blood vessels guide Schwann cell-mediated regeneration of peripheral nerves. Cell. 2015; 162:1127-1139. [PubMed: 26279190]

54. Kwee BJ, Mooney DJ. Manipulating the intersection of angiogenesis and inflammation. Annals of biomedical engineering. 2015; 43:628-640. [PubMed: 25316589]

55. Cosgrove BD, Gilbert PM, Porpiglia E, Mourkioti F, Lee SP, Corbel SY, Llewellyn ME, Delp SL, Blau HM. Rejuvenation of the aged muscle stem cell population restores strength to injured aged muscles. Nature medicine. 2014; 20:255-264.

56. Kuswanto W, Burzyn D, Panduro M, Wang Kathy K, Jang Young C, Wagers Amy J, Benoist C, Mathis D. Poor Repair of Skeletal Muscle in Aging Mice Reflects a Defect in Local, Interleukin-33-Dependent Accumulation of Regulatory T Cells. Immunity. 2016; 44:355-367. [PubMed: 26872699]

57. Lukjanenko L, Jung MJ, Hegde N, Perruisseau-Carrier C, Migliavacca E, Rozo M, Karaz S, Jacot G, Schmidt M, Li L, et al. Loss of fibronectin from the aged stem cell niche affects the regenerative capacity of skeletal muscle in mice. Nat Med. 2016; 22:897-905. [PubMed: 27376579] 


\section{Highlights}

- Overview of the natural process of skeletal muscle regeneration

- $\quad$ Biomaterials can be combined with muscle cells and other supporting cell types

- $\quad$ Biomaterials can provide signals to host cells to drive muscle regeneration in situ 

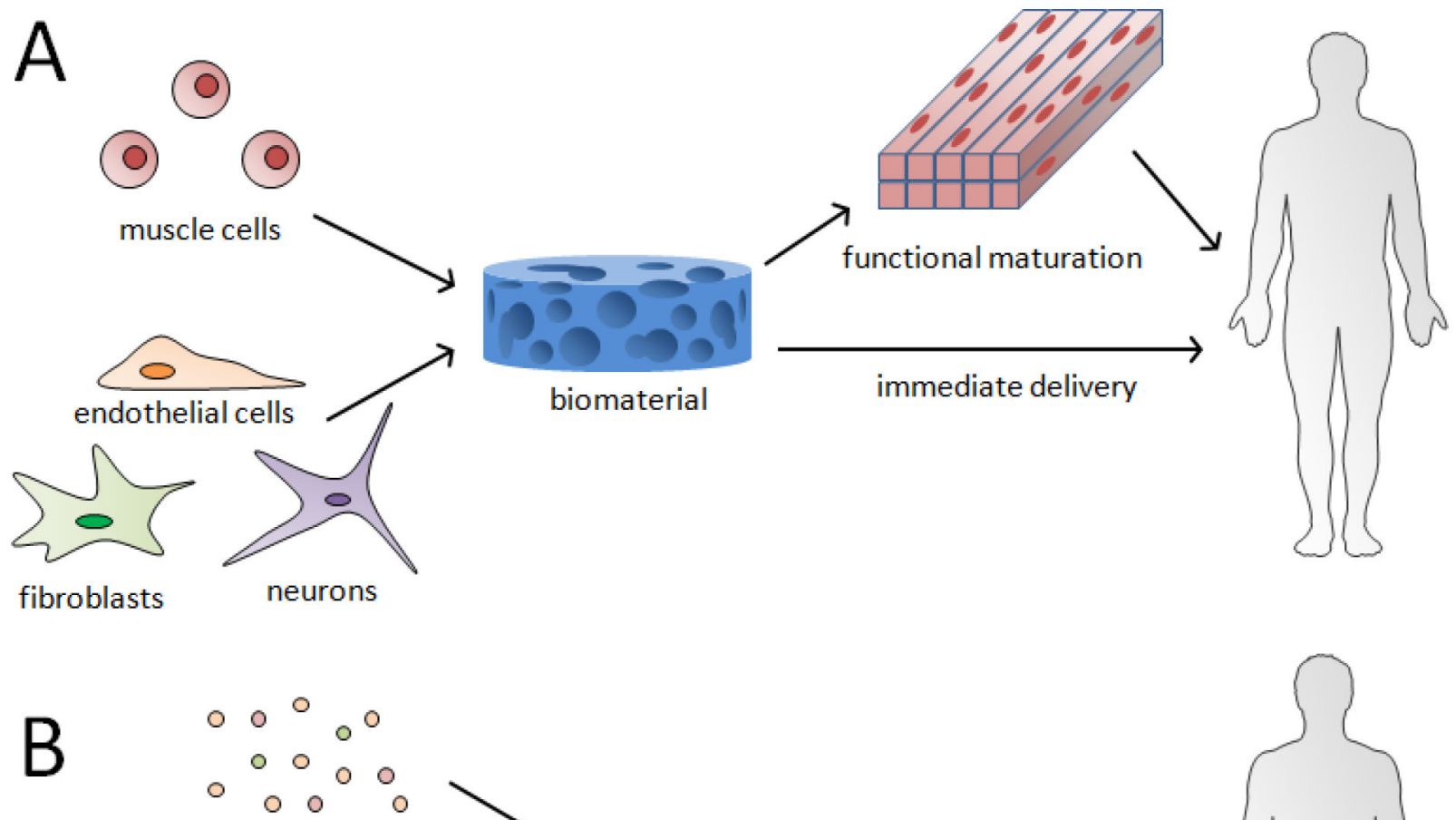

cytokines \& growth factors



biomaterial
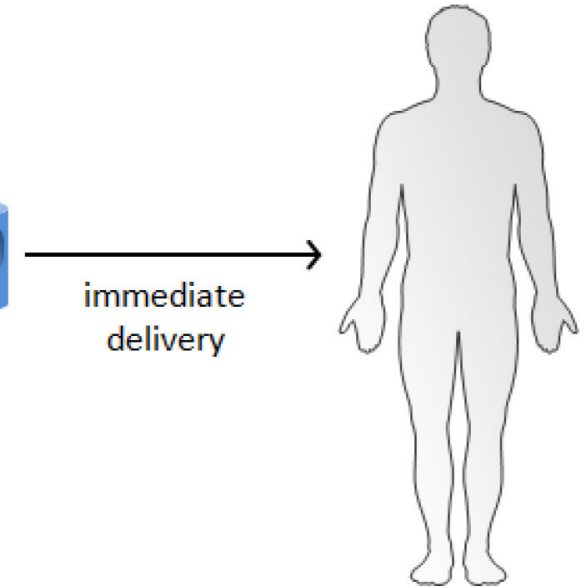

paracrine signaling cells

Figure 1.

Two general approaches of skeletal muscle tissue engineering. (A) Muscle cells and other supporting cells are combined with biomaterials in vitro, followed by transplantation either after extended culture to promote muscle formation, or immediately. (B) Biomaterials, either alone or combined with cytokines, growth factors, or cells secreting paracrine signals, are delivered to the body to induce regeneration by host muscle cells. 
A

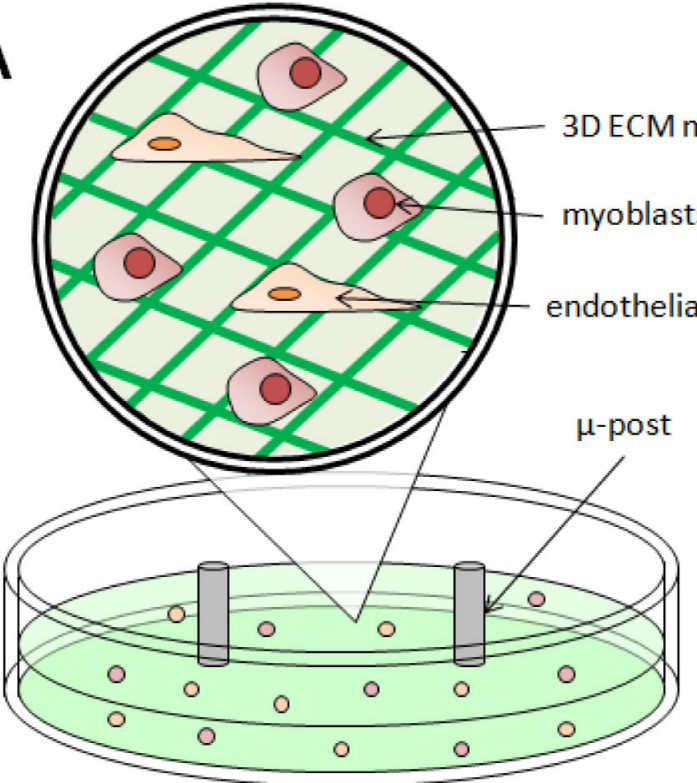

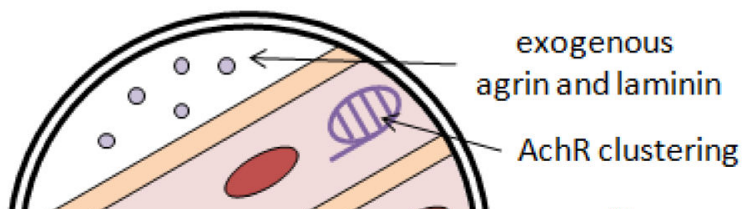

exogenous

AchR clustering

myofiber endothelial vessel

B
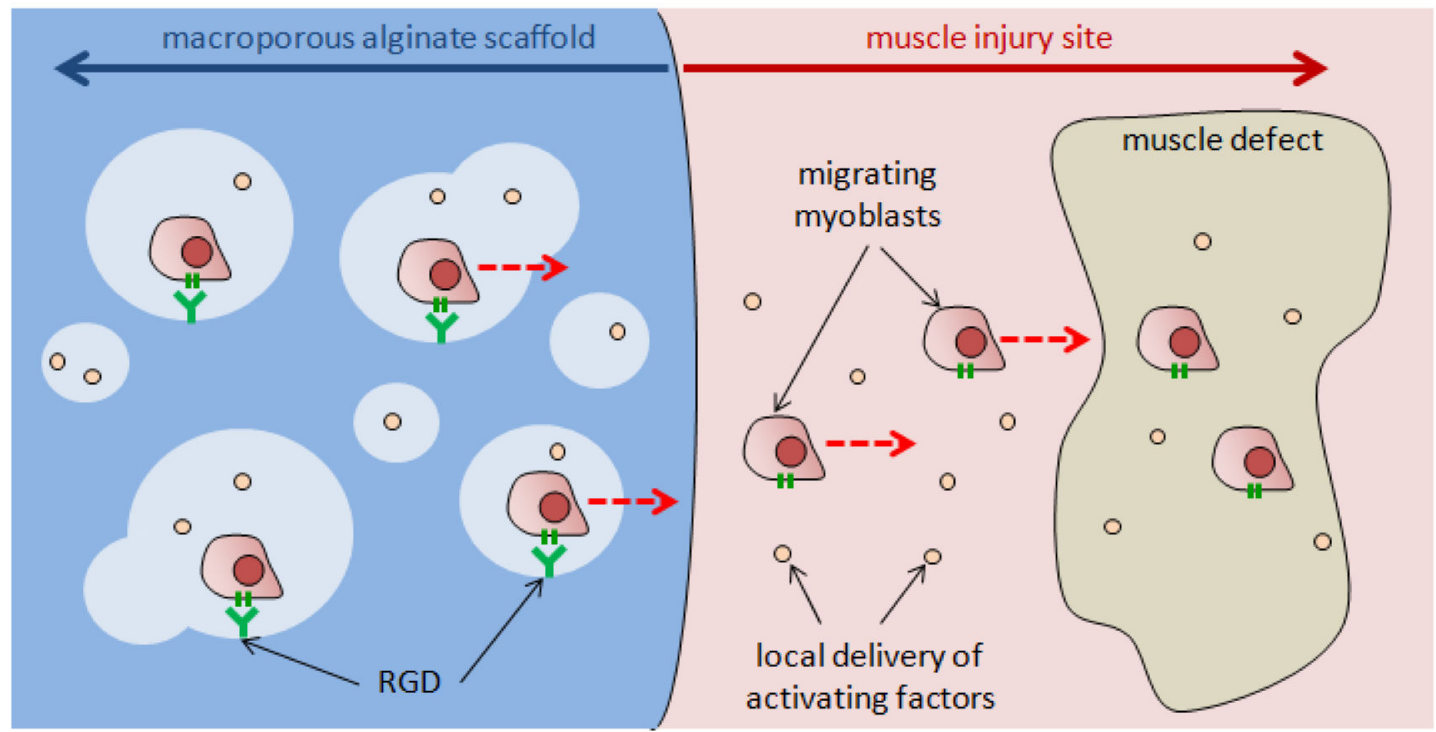

Figure 2.

Examples of muscle cells combined with biomaterials. (A) Engineered skeletal muscle consisting of myoblasts seeded into a fibrin gel, with microposts acting as artifical tendons that aid in forming aligned myofibers. These engineered muscles may also include endothelial cells that form aligned vascular networks, and/or exogenous agrin and laminin to promote acetylcholine receptor clustering. (B) Macroporous alginate scaffold (left) immediately delivering myoblasts to an adjacent muscle injury site (right). This scaffold is modified with RGD peptides to promote myoblast adhesion to the material and also releases factors to promote myoblast migration and proliferation. Red, dotted arrows indicate direction of cell migration. 

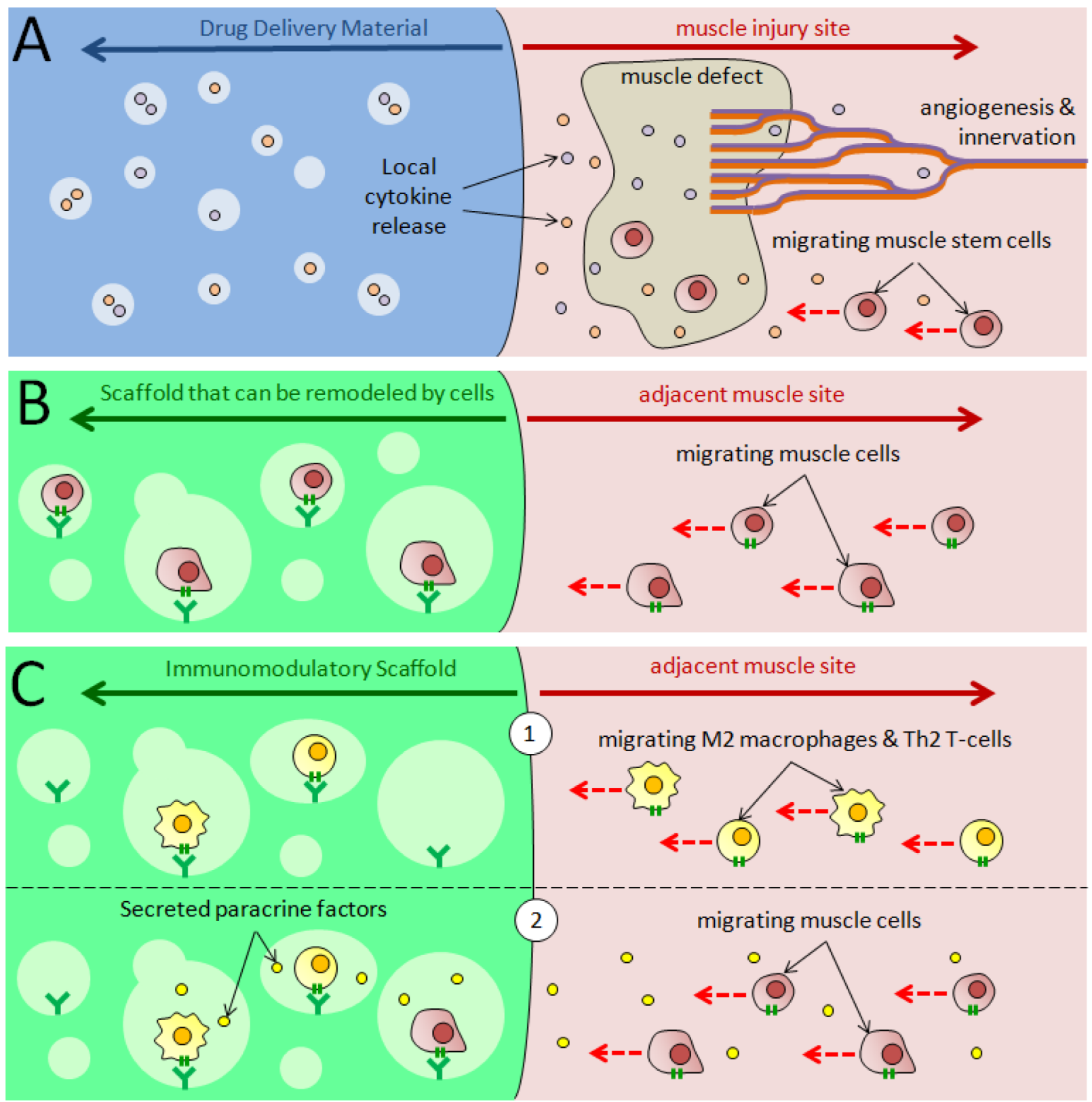

Figure 3.

Different approaches to in situ skeletal muscle tissue engineering. (A) Controlled growth factor release from drug delivery biomaterial (left) to adjacent injured muscle (right) can promote muscle stem cell recruitment, as well as host innervation and angiogenesis. (B) Materials that can be remodeled by cells (left) can naturally drive in-growth of muscle cells in the absence of growth factors from adjacent muscle (right). (C) Immunomodulatory biomaterials (left) placed adjacent to muscle (right) can (1) recruit host anti-inflammatory M2 macrophages and Th2 T-cells. Following recruitment, (2) these cells can secrete paracrine factors to recruit host muscle cells to the material and/or drive endogenous muscle regeneration. Red, dotted arrows indicate direction of cell migration. 